\title{
An observational study of maternal and fetal outcome in pregnant women with Hepatitis $\mathrm{E}$
}

\author{
Ranjana Mishra*, Arun H. Nayak, Madhuri Mehendale
}

Department of Obstetrics and Gynecology, Lokmanya Tilak Municipal Medical College and General Hospital, Sion, Mumbai, Maharashtra, India

Received: 17 May 2019

Accepted: 01 July 2019

*Correspondence:

Dr. Ranjana Mishra,

E-mail: mranjana478@gmail.com

Copyright: (c) the author(s), publisher and licensee Medip Academy. This is an open-access article distributed under the terms of the Creative Commons Attribution Non-Commercial License, which permits unrestricted non-commercial use, distribution, and reproduction in any medium, provided the original work is properly cited.

\begin{abstract}
Background: Hepatitis E in pregnancy has been a subject of interest in the recent years as the available research work is very limited and conflicting especially in pregnant women as compared to infection in men and non-pregnant women in which the disease is usually self- limiting. The mechanism of liver injury in hepatitis $\mathrm{E}$ is not clear and no conclusive theories about the exact pathogenesis are available. This study was done to gain insight into the effects of hepatitis $\mathrm{E}$ virus on pregnancy in terms of maternal and fetal outcome.

Methods: Total of 40 pregnant women with Hepatitis E Virus IgM antibodies was included in the study. Hepatitis cases due to other viral and non-infective causes were excluded. Maternal outcomes in terms of mode of delivery, complications like PPH, hepatic encephalopathy, fulminant hepatic failure, coagulopathy and maternal mortality was studied. Fetal outcomes in terms of intrauterine fetal deaths, stillbirth, live births, and neonatal deaths were studied.

Results: This study showed high mortality rates $(42.5 \%)$ in pregnant women with hepatitis E. The most common obstetric complication was IUFD (45\%) followed by preterm labor $(32.5 \%)$ and postpartum hemorrhage $(22.5 \%)$. Hepatic encephalopathy $(62.5 \%)$ was the commonest medical complication followed by coagulopathy (25\%). A statistically significant association was found between the presence of medical complications and poor maternal outcome.

Conclusions: Hepatitis E virus infection in pregnancy often has a fulminant course with poor maternal and fetal outcome. Its management therefore requires an early diagnosis, and a multidisciplinary approach.
\end{abstract}

Keywords: Hepatitis E Virus, Hepatic encephalopathy, IgM antibodies, Intrauterine fetal deaths, Maternal mortality, Postpartum hemorrhage

\section{INTRODUCTION}

In the modern era of Obstetrics, more emphasis is being laid on medical disorders in pregnancy like hepatitis especially, hepatitis $\mathrm{E}$ due to its unique course during pregnancy. Hepatitis $\mathrm{E}$ virus is predominantly transmitted through feco-oral route by drinking contaminated water and also by ingesting products derived from ingestion of raw and uncooked shellfish, transfusion of infected blood products, vertical transmission from pregnant women to their babies at the time of delivery.

Hepatitis E virus (HEV) is a small, non-enveloped virus with a single-stranded, positive- sense RNA genome that is approximately $7.2 \mathrm{~kb}$ in size and contains three partially overlapping frame that are bracketed by short 5 . and 3 non-translated regions., ${ }^{1,2} \mathrm{HEV}$ is known to have five genotypes; genotypes 1 and 2 are more virulent and 
restricted to humans while genotypes 3 and 4 are zoonotic, more attenuated and accountable for subclinical infection. $^{3}$ Although, originally classified within the family of caliciviruses, but now they are categorised under family hepeviridae. Incubation period following exposure to hepatitis E virus is 2-9 weeks with a mean of 45 days. $^{4,5}$

HEV has an interesting course in pregnant women as significant proportion of these women can progress to fulminant hepatic failure. Pregnant women, particularly in second and third trimesters are affected more frequently during epidemics with very high mortality rates. It is a challenging disease for the Obstetricians because of the obstetric complications such as antepartum hemorrhage (APH), postpartum hemorrhage (PPH), preterm labor, preterm premature rupture of membranes (PPROM), coagulopathy and fetal complications like intrauterine fetal death (IUFD), prematurity, hypoglycaemia, and need of intensive care units.

Various attributing factors have been proposed like immunological changes in the form of suppressed $\mathrm{T}$-cell mediated immunity, hormonal factors which may promote viral replication and inhibit hepatic cells thus predisposing pregnant women to hepatic dysfunction and failure. The purpose of our study was to prospectively evaluate maternal and fetal outcome in HEV infected pregnant women.

\section{METHODS}

An observational prospective study was conducted in the Department of Obstetrics and Gynecology at Lokmanya Tilak Municipal Medical College and General Hospital, a tertiary care centre over a period of one year from October 2016 to October 2017.

The proposed study had a sample size of 40 patients. Ethical approval of the study protocol was obtained from the Institutional Ethics Committee.

\section{Inclusion criteria}

- The All pregnant women with jaundice with positive Hepatitis E $\operatorname{IgM}$ antibodies were included in the study.

\section{Exclusion criteria}

Other viral causes: Hepatitis A, B, C etc.

Non-infective causes

- Pregnancy induced hypertension and HELLP syndrome

- Cholestasis of pregnancy

- Acute fatty liver

- Chronic liver disease
- Hematological disorders - hemolytic anemias, sickle cell anemia, thalassemias etc.

All pregnant patients visiting antenatal outpatient department or admitted, with jaundice and HEV IgM positive, were subjected to detailed history about the age, obstetric history, gestational age based on the last menstrual period, present and past history. Any previous history of blood and blood products transfusion, any invasive procedure or prolonged hospital stay in the past was also taken. A detailed clinical examination was carried out which included pulse, BP, pallor, icterus, respiratory system, cardiovascular system and central nervous system examination, fetal heart sounds, abdominal palpation, per vaginum examination. All the patients were subjected to biochemical investigations including complete blood count, liver function tests (serum bilirubin, AST, ALT, alkaline phosphatase), prothrombin time with INR, obstetrical ultrasound. Special investigations like viral markers including HBsAg antigen, anti- HAV IgM, anti- HCV, anti- HEV IgM antibodies were done in all patients. All the patients who were positive for IgM antibodies of hepatitis E virus (HEV), were included in the study. Intrapartum and postpartum maternal complications were noted. Fetal outcome was also observed.

\section{Statistical analysis}

Statistical analysis was performed using SPSS 16.0 The data analysis was computer based and data entry sheet was designed in Microsoft excel 2013 and statistical analysis was done using spss version 20.0. Qualitative data was analysed using frequency and percentage and quantitative data by mean and standard deviation. Association between two qualitative variables was done by Chi- square test and a ' $p$ ' value less than 0.05 was considered as significant.

\section{RESULTS}

\section{Characteristics of study group}

Out of total 40 patients enrolled for our study, 27 (67.5\%) patients were in 26-30year age group followed by 9 $(22.5 \%)$ in 20-25year group. There were $3(7.5 \%)$ patients in 31-35year group and only 1 patient $(2.5 \%)$ belonged to above 36year group. The mean age of patients at presentation of illness in our study was $27 \pm 3.37$ years.

Table 1: Age distribution.

\begin{tabular}{|lll|}
\hline Age & Frequency & Percentage \\
\hline 20-25 years & 9 & $22.5 \%$ \\
\hline 26-30 years & 27 & $67.5 \%$ \\
\hline $31-35$ years & 3 & $7.5 \%$ \\
\hline 36 and above & 1 & $2.5 \%$ \\
\hline
\end{tabular}


Table 2: Distribution of cases as per mode of delivery.

\begin{tabular}{|lll|}
\hline Mode of delivery & Frequency & Percentage \\
\hline Vaginal & 36 & $90 \%$ \\
\hline LSCS & 2 & $5 \%$ \\
\hline Undelivered & 2 & $5 \%$ \\
\hline
\end{tabular}

In our study, 36 out of $40(90 \%)$ patients delivered vaginally while 2 patients $(5 \%)$ underwent lower segment cesarean section (LSCS). The indications were - thick meconium stained liquor with fetal distress (1) and bleeding placenta previa (1). All 7 patients who were induced delivered vaginally.

Table 3: Distribution of cases as per INR value.

\begin{tabular}{|lll|}
\hline & Frequency & Percentage \\
\hline INR $>1.5$ & 28 & $70 \%$ \\
\hline INR $<1.5$ & 12 & $30 \%$ \\
\hline
\end{tabular}

\section{Distribution of cases as per INR value}

In our study, 28 out of 40 patients (70\%) had INR (International normalised ratio) values more than 1.5 and 12 patients $(30 \%)$ had INR values below 1.5. INR ranged from 1.2 to 7.4 and median INR was 2.1 . However, only 10 patients out of $40(25 \%)$ had clinically significant coagulopathy with bleeding tendencies which required transfusion of blood and blood products.

Table 4: Distribution of cases as per maternal outcome.

\begin{tabular}{|lll|}
\hline Maternal outcome & Frequency & Percentage \\
\hline Died & 17 & $42.5 \%$ \\
\hline Discharged & 13 & $57.5 \%$ \\
\hline
\end{tabular}

Table 5: Comparison of maternal mortality rates in various studies.

\begin{tabular}{|c|c|}
\hline Study & Maternal mortality rates \\
\hline Khuroo et al ${ }^{12}$ & $55 \%$ \\
\hline Banait et al ${ }^{11}$ & $54 \%$ \\
\hline Yadav et $\mathrm{al}^{7}$ & $52 \%$ \\
\hline Patra et $\mathrm{al}^{6}$ & $41 \%$ \\
\hline Tahira et al $^{8}$ & $29.3 \%$ \\
\hline Jethwa et $\mathrm{al}^{9}$ & $20.5 \%$ \\
\hline Prasad et al ${ }^{10}$ & $5.45 \%$ \\
\hline Our study & $42.5 \%$ \\
\hline
\end{tabular}

In our study, the maternal mortality rate was 17 out of 40 i.e. $42.5 \%$ which is comparable to Patra et al, done in New Delhi in which out of 132 hepatitis E positive women, 54 died $(41 \%)$ and Yadav et al, in which $52 \%$ expired. ${ }^{6,7}$ The higher mortality rates in our study could be due to more patients presenting with hepatic encephalopathy and fulminant hepatic failure at admission itself which had a very grave prognosis and also due to non- availability of liver transplantation facilities in our hospital.

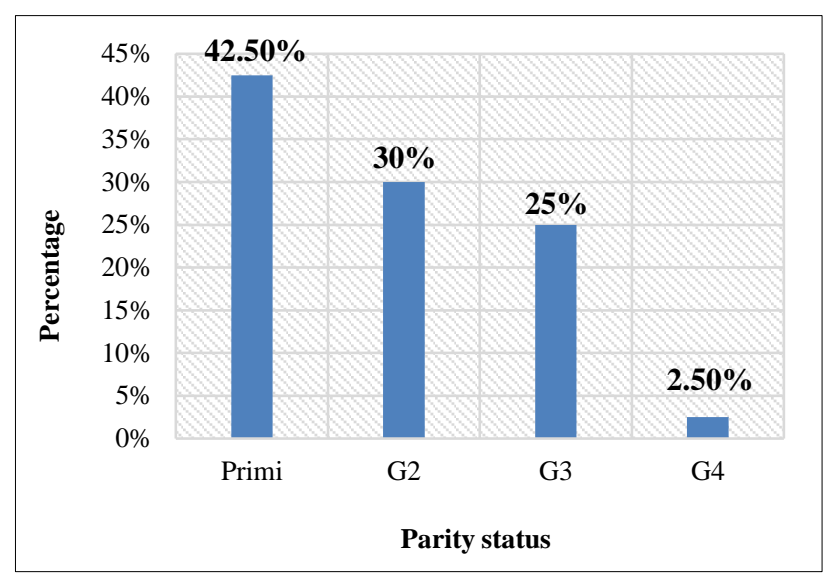

Figure 1: Distribution of cases as per parity.

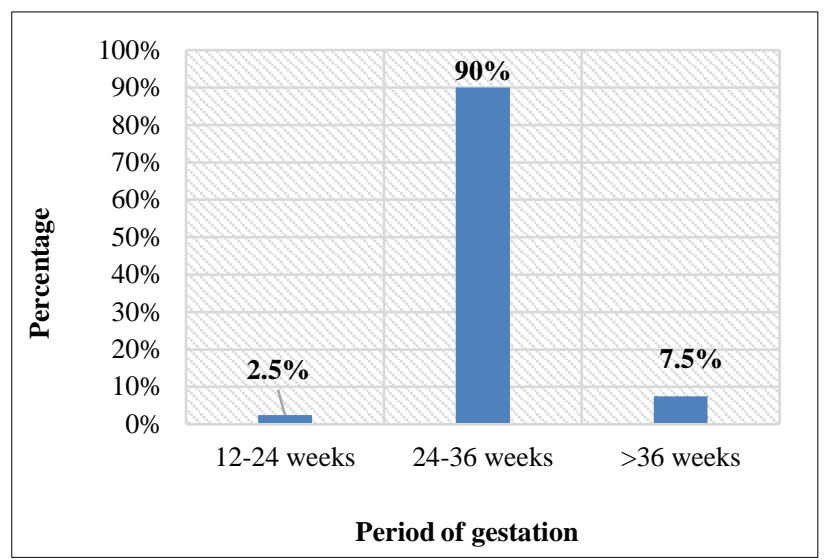

Figure 2: Distribution of cases as per period of gestation.

In our study, 17 out of $40(42.5 \%)$ patients were primigravida and rest $23(57.5 \%)$ were multigravida out of which $12(30 \%)$ and $10(25 \%)$ belonged to second and third gravida group respectively. Only 1 (2.5\%) patient was fourth gravida.

In our study, 36 out of $40(90 \%)$ patients belonged to $24-$ 36 weeks gestational age group, $3(7.5 \%)$ were in more than 36 weeks group and only $1(2.5 \%)$ patient in $12-24$ weeks group. There was no patient in first trimester. The mean gestational age was $31.85 \pm 3.34$ weeks and minimum gestational age being 23.6 weeks and maximum 39.2 weeks

In our study, 31 out of $40(77.5 \%)$ patients had spontaneous onset of labor while $7(17.5 \%)$ patients required induction of labor. The indications for induction were: Intrauterine fetal demise (IUFD) with PROM in 6 out of 7 patients and PROM with oligohydramnios in 1 patient with live fetus. There were 2 patients who expired before delivery. 


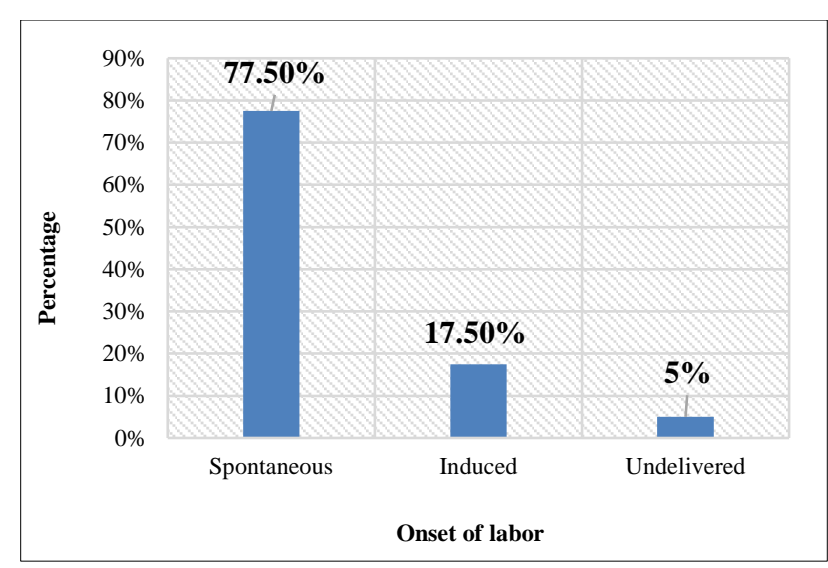

Figure 3: Distribution of cases as per onset of labor.

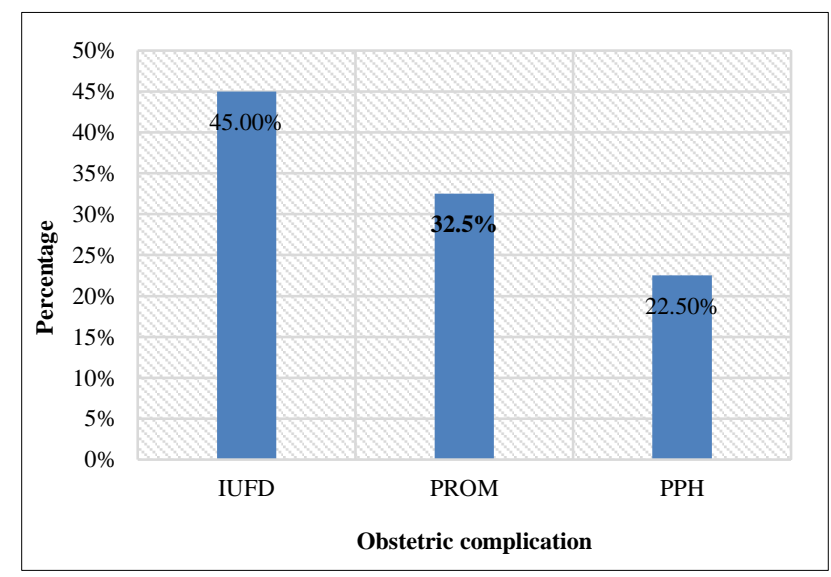

Figure 4: Distribution of cases as per obstetric complication.

Most common obstetric complication in our study, was intrauterine fetal demise (IUFD) which was seen in 18 out of 40 women $(45 \%)$. Out of total 18 intrauterine deaths, 14 had IUFD at admission, referred from various peripheral health centres and rest 4 patients had IUFD during their stay in hospital. Next most common complication was premature rupture of membranes and preterm labor which was seen in 13 out of $40(32.5 \%)$ followed by postpartum hemorrhage (PPH) seen in 9 $(22.5 \%)$ patients. Most of the patients with $\mathrm{PPH}$ were given medical management except one patient who was taken up for an emergency LSCS for bleeding placenta previa and had atonic PPH intra-operatively and therefore an obstetric hysterectomy was done, after medical management failed.

In our study, hepatic encephalopathy was found to be the most common medical complication which was seen in 25 out of 40 patients $(62.5 \%)$. Hepatic encephalopathy alone was seen in 15 out of 40 patients $(37.5 \%)$ while 10 out of 40 patients $(25 \%)$ with hepatic encephalopathy, developed fulminant hepatic failure complicating the course of disease. 10 patients (25\%) had coagulation abnormalities and required blood and blood products like fresh frozen plasma, cryoprecipitates etc. However, 5 patients $(12.5 \%)$ had no medical complication.

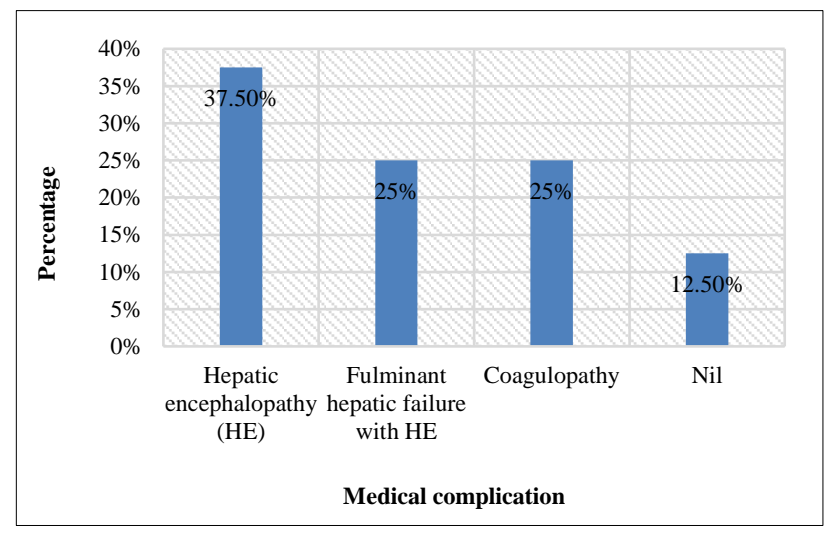

Figure 5: Distribution of cases as per medical complication.

Most patients with advanced hepatic encephalopathy especially if associated with hepatic failure, were managed in intensive care units with supportive care. Of total 15 patients with hepatic encephalopathy, 11 $(73.33 \%)$ recovered and were discharged while 4 (26.7\%) patients expired. In contrast, patients who had fulminant hepatic failure superimposed on hepatic encephalopathy, only 2 out of $10(20 \%)$ patients recovered while 8 patients $(80 \%)$ died. In 10 patients with Coagulopathy, 5 $(50 \%)$ recovered and rest $5(50 \%)$ died. All the 5 patients who had no associated medical complications were managed in wards, all recovered from the illness and were discharged.

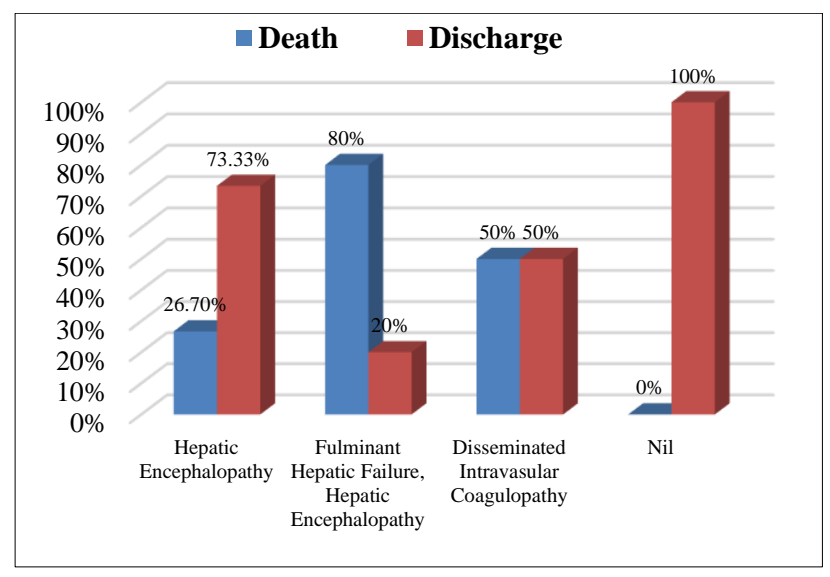

Figure 6: Association of medical complications and maternal outcome.

The association of presence of hepatic failure with poor maternal outcome is statistically significant ( $p$ value of $0.00053)$.

In this study out of total 40 patients, 18 babies died inutero $(45 \%)$ including two patients who had IUFD but died undelivered, 19 were live births (47.5\%) and 3 (7.5\%) babies were stillbirths. 


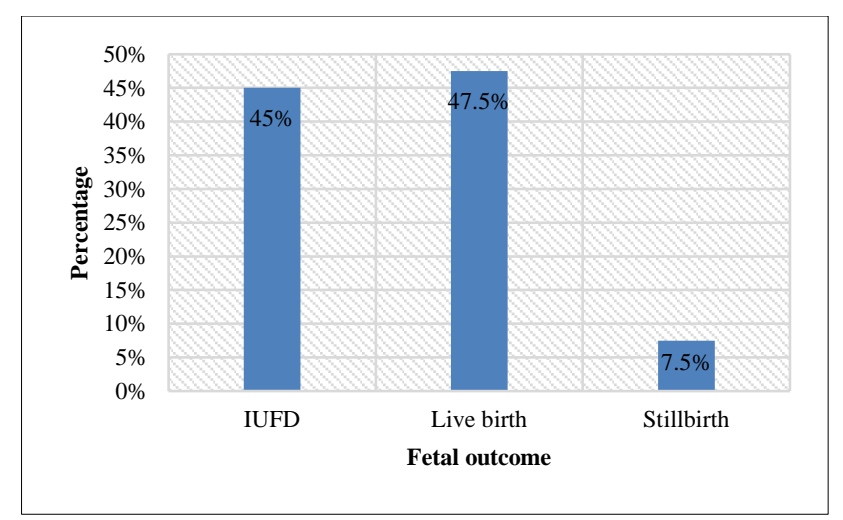

Figure 7: Distribution of cases as per fetal outcome.

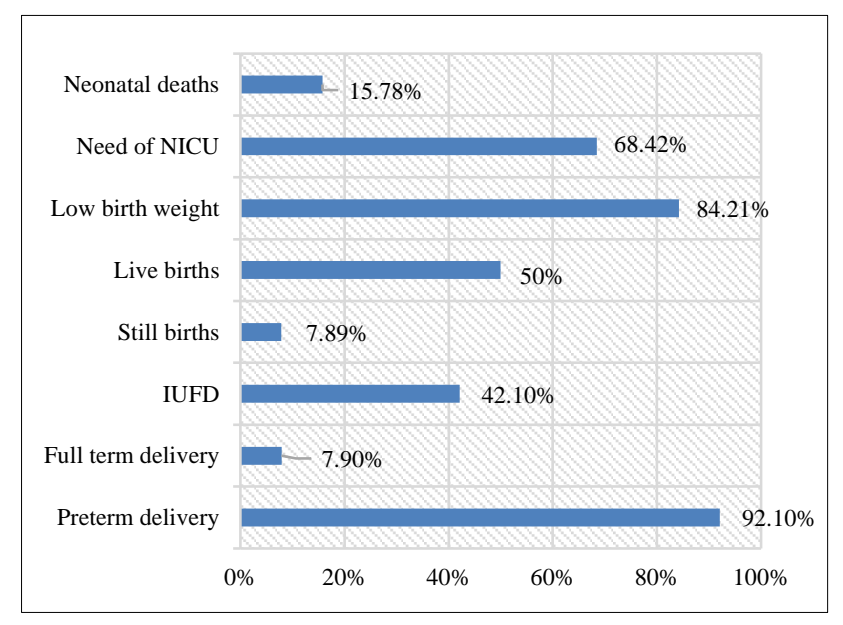

Figure 8: Distribution of cases as per perinatal outcome.

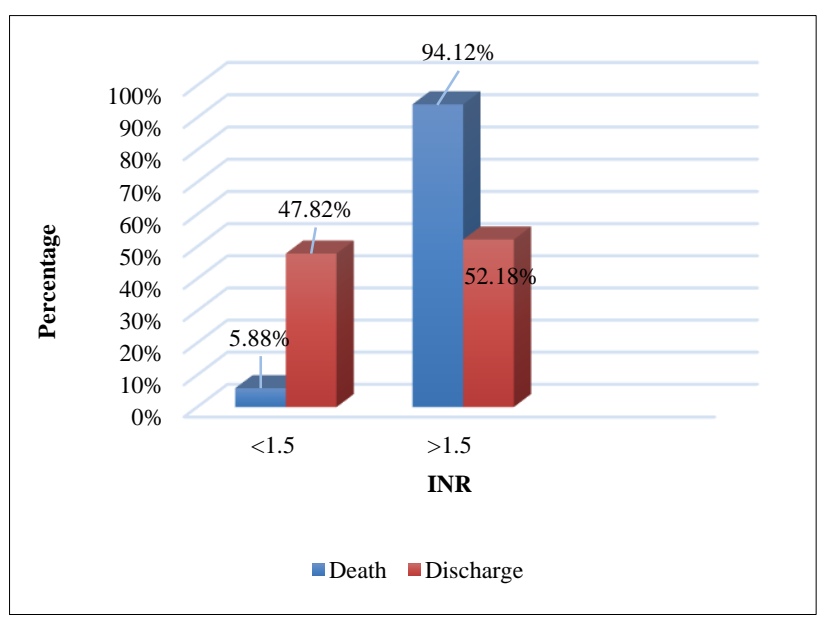

Figure 9: Association of INR and maternal outcome.

Out of total 38 babies delivered, 35 (92.1\%) were preterm deliveries and only $3(7.9 \%)$ were full term births. Out of 35 preterm births, 28 were spontaneous while 7 were induced for indications like IUFD, PROM and oligohydramnios. All the induced patients delivered vaginally. 19 out of 38 delivered (50\%) were live births and 13 babies $(68.42 \%)$ were admitted in NICU
(Neonatal intensive care unit) in view of preterm and prematurity (11 out of 13) and meconium stained liquor ( 2 out of 13). Out of total 13 NICU admissions, 3 babies expired due to necrotizing enterocolitis (1), sepsis (1), prematurity with respiratory distress syndrome (1) thus, accounting for total 3 neonatal deaths $(15.78 \%)$. Out of total 19 live births, $16(84.21 \%)$ were low birth weight i.e. birth weight less than $2500 \mathrm{gm}$.

In the discharged group (23 out of 40), 12 (52.18\%) patients had INR $>1.5$ and $11(47.82 \%)$ patients had INR $<1.5$ while in died group (17 out of 40) patients 16 $(94.12 \%)$ belonged to INR $>1.5$ group and only 1 $(5.88 \%)$ belonged to $<1.5$ group. So the association between INR > 1.5 and maternal mortality was significant ( $\mathrm{p}$ value- 0.0042 ).

\section{DISCUSSION}

\section{Age distribution and parity status}

In this study, the maximum patients $(67.5 \%)$ were found in the age group of 26 to 30 years which was similar to Tahira et al, and $42.5 \%$ patients were primigravidas which was similar to Jethwa et al. ${ }^{8,9}$

\section{Period of gestation}

In this study, $90 \%$ patients were in 24-36weeks gestational age group. This observation is similar to Yadav et al and other previous studies, which showed increasing incidence as gestational age increases. ${ }^{7}$

\section{Obstetric complications}

In our study, IUFDs was the commonest obstetric complication, seen in 18 of $40(45 \%)$ patients out of which 14 were detected as IUFD at admission itself and rest 4 had IUFD during hospital stay. The pregnancy in these 4 patients was not terminated because of poor general condition and hemodynamic instability at admission. Out of these 4, two patients presented with advanced grades of hepatic encephalopathy, had IUFD and fulminant hepatic failure on day 2 and died undelivered on day 3 of admission. Third patient presented with hepatic encephalopathy and hepatic failure at admission itself and had 1 episode of generalized tonic clonic seizures followed by IUFD (within 10 hours of admission). Fourth patient was a known case of Rheumatic heart disease with Balloon mitral valvotomy (BMV) done, presented with hepatic encephalopathy and failure. She had IUFD 6 hours after admission and died on day 2. Next common complication was premature rupture of membranes and preterm labor which was seen in $32.5 \%$ followed by postpartum haemorrhage (PPH) seen in $22.5 \%$ patients. All the patients who had PPH required blood or blood products transfusion. It is similar to Patra et al, where IUFD was seen in 77 out of $132(58 \%) \mathrm{HEV}$ infected pregnant women. ${ }^{6}$ 


\section{Medical complications and its association with maternal outcome}

The most common medical complication in this study was hepatic encephalopathy, seen in $62.5 \%$ patients out of which $25 \%$ had fulminant hepatic failure superimposed on hepatic encephalopathy. The association between medical complication and maternal outcome was studied. Out of total 10 patients with fulminant hepatic failure, $80 \%$ patients expired and only $20 \%$ patients survived. ${ }^{2,8}$ This was found to be statistically significant with $\mathrm{p}$ value of 0.00053 . We observed that all patients without medical complications were discharged and also did not require admission to intensive care units. Thus, it can be concluded from this study that mortality rates were higher in HEV infected women with medical complications compared to those without these complications. Coagulopathy was the second most common complication seen in $25 \%$ patients in our study while in Yadav et al, coagulopathy was the most common complication (56\%). ${ }^{7}$ In our study, $85 \%$ patients required admissions to intensive care, either directly $(62.5 \%)$ or transferred from medical or labor wards $(22.5 \%)$ during their stay in hospital. It was similar to Tahira et al, with $60 \%$ ICU admissions. ${ }^{8}$

\section{INR and its association with maternal outcome}

In our study, out of total 12 patients with INR $<1.5,11$ $(91.67 \%)$ were discharged while only $1(8.33 \%)$ patient died. In contrast, out of total 28 patients with INR $>1.5$, $16(57.14 \%)$ died and $12(42.86 \%)$ were discharged. This difference was found to be statistically significant with $\mathrm{p}$ value 0.0042 . It was similar to Yadav et al. in which the mean INR was significantly higher in the expired group as compared to the discharged group. ${ }^{7}$

\section{Onset of labor and mode of delivery}

About $77.5 \%$ patients in our study went in spontaneous labor and only 7 patients out of 40 were induced only for indications like IUFDs with PROM (6) and oligohydramnios (1). Induction rates were higher than Prasad et al, due to more number of patients presenting with IUFDs at the time of admission. ${ }^{10}$ All the patients who were induced, delivered vaginally similar to Prasad et al. ${ }^{10}$ Caesarean section was reserved only for obstetric indications - bleeding placenta previa (1) and thick meconium stained liquor and fetal distress (1), done in total 2 patients. Rest all $90 \%$ patients delivered vaginally. It was similar to Prasad et al, and Jethwa et al, In Banait et al, 42 patients with acute liver failure due to hepatitis $\mathrm{E}$ were retrospectively analyzed and all patients delivered by vaginal route. ${ }^{9-11}$

\section{Fetal outcome}

19 out of $38(47.5 \%)$ were live births. However, 35 out of $38(92.1 \%)$ were preterm deliveries and 13 babies $(68.42 \%)$ required admission to NICUs. There were 3 neonatal deaths due to extreme prematurity and related complications like respiratory distress syndrome, necrotizing enterocolitis and sepsis. It was comparable to Patra et al. ${ }^{6}$ There were 22 perinatal deaths in our study which included 16 IUFDs, 3 stillbirths and 3 early neonatal deaths. The total perinatal mortality rate in our study was 57.89 per 1000 total births which was higher as compared to Tahira et al, (30.3 per 1000 total births) probably due to more number of patients presenting with hepatic encephalopathy and IUFDs at admission itself. ${ }^{8}$ In Banait et al, fetomaternal outcome in 42 women with acute liver failure due to hepatitis $\mathrm{E}$ was studied and there were $69 \%$ fetal deaths which was explained by higher grades of encephalopathy at admission. ${ }^{11}$

\section{Maternal outcome}

The maternal mortality rates were $42.5 \%$ in our study despite best possible care in the intensive care units at our centre. This was probably due to higher number of patients being referred from peripheral health centres with advanced grades of hepatic encephalopathy or fulminant hepatic failure at the time of admission, nonavailability of obstetric ICU and liver transplantation facility in our hospital.

There is no one consensus till date for reasons of fulminant course of hepatitis $\mathrm{E}$ in pregnancy.

Pal et al, found that pregnant women with HEV had generalized immune suppression characterized by decrease in lymphocyte response to phytohemagglutinin (PHA) with a predominant Th2 bias as compared to nonpregnant women and normal healthy controls. ${ }^{13}$ Navneethan et al, hypothesized that the difference in the genotype or its subtypes of the Hepatitis E virus infection could be the reason for difference in mortality rates of various studies. ${ }^{14}$ Khuroo et al, suggested that vertical transmission of HEV to the fetus may be responsible for the increased severity of the disease in the mother. ${ }^{12}$ All the studies have shown that pregnant women have the differential immune response which triggers fulminant liver failure. So the logical treatment should be to deliver the fetus as soon as possible. Unfortunately, very few such studies have been undertaken in this field. Thus, there is need of more such studies for better understanding of hepatitis $\mathrm{E}$ virus and its exact pathogenesis in pregnancy.

\section{CONCLUSION}

Our study concludes that Hepatitis E virus infection in pregnancy has a poor maternal as well as fetal outcome even in a tertiary care centre, like ours. A high index of suspicion, early diagnosis, prompt referral to a higher centre when required, availability of blood and blood products, and a proactive policy of early delivery when indicated, can improve both maternal as well as fetal outcome in pregnant women with hepatitis E. The observed variation in maternal morbidity and mortality 
rates between various studies indicate the need to subtype the viral genotype according to its virulence and morbidity. Unfortunately, the role of therapeutic termination of pregnancy in the treatment of liver failure due to hepatitis $\mathrm{E}$ has not been studied thoroughly, a measure that has been shown to be useful in liver failure due to acute fatty liver of pregnancy. This highlights the need of more prospective studies on role of termination of pregnancy on feto-maternal outcome in women with hepatitis $\mathrm{E}$, which can help in reducing the grave burden of this disease in years to come.

Funding: No funding sources

Conflict of interest: None declared

Ethical approval: The study was approved by the Institutional Ethics Committee

\section{REFERENCES}

1. Mellor AL, Sivakumar J, Chandler P. Prevention of $\mathrm{T}$ cell driven complement activation and inflammation by tryptophan catabolism during pregnancy. Nat Immunol. 2001;2:64.

2. Orsi NM, Gopichandran N, Ekbote UV, Walker JJ. Murine serum cytokines throughout the estrous cycle, pregnancy and post-partum period. Anim Reprod Sci. 2006;96:54-65.

3. Kasper L, Fauci J. Acute viral hepatitis. Harrison's Princ Intern Med. 2015;2(18):2537-55.

4. Krawczynski K, Aggarwal R, Kamili S. Hepatitis E. Infect Dis Clin North Am. 2000;14:669-87.

5. Tsarev SA, Tsareva TS, Emerson SU. Infectivity titration of a prototype strain of Hepatitis E virus in cynomolgus monkeys. J Med Virol. 1994;43:135-42.

6. Patra S, Kumar A, Trivedi SS, Puri M, Sarin SK. Maternal and fetal outcomes in pregnant women with acute hepatitis E virus infection. Ann Intern Med. 2007; 147:28-33.
7. Yadav S. Maternal and fetal outcome in pregnancy with hepatitis $\mathrm{E}$ virus infection. Int $\mathrm{J}$ Reprod Contracept Obstet Gynecol. 2016;5(10):3482-90.

8. Naru T, Yousuf F, Malik A, Naz S, Ismail H. Comparison of foeto-maternal outcome in pregnant women with hepatitis E-A review of 12 years. J Pak Med Asso: JPMA. 2017;67(4):538.

9. Jethwa DK, Chauhan DV, Badrakiya GL, Badrakiya SG. Hepatitis E virus in pregnancy with fetomaternal outcome-A prospective study. IOSR. 2015;14(8):258.

10. Prasad GS, Prasad S, Bhupali A, Patil AN, Parashar K. A study of Hepatitis E in pregnancy: Maternal and fetal outcome. J Obstet Gynecol India. 2016;66(1):18-23.

11. Banait VS, Sandur V, Parikh F. Outcome of acute liver failure due to acute hepatitis $\mathrm{E}$ in pregnant women. Indian J Gastroenterol. 2007;26:6-10.

12. Khuroo MS, Kamili S, Yattoo GN. Severe fetal hepatitis $\mathrm{E}$ virus infection is the possible of increased severity of hepatitis $\mathrm{E}$ virus infection in the mother: another example of mirror syndrome. Indian $\mathbf{J}$ Gastroenteral. 2004;23(Suppl. 1):A1.

13. Pal R, Aggarwal R, Naik SR, Das V, Das S, Naik S. Immunological alterations in pregnant women with acute hepatitis E. J Gastroenterol Hepatol. 2005;20:1094-101.

14. Navaneethan U, Al Mohajer M, Shata MT. Hepatitis $\mathrm{E}$ and pregnancy: understanding the pathogenesis. Liver Int. 2008;28(9):1190-9.

Cite this article as: Mishra R, Nayak $\mathrm{AH}$, Mehendale M. An observational study of maternal and fetal outcome in pregnant women with Hepatitis E. Int J Reprod Contracept Obstet Gynecol 2019;8:3110-6. 